\title{
NUCLEOSSÍNTESE PRIMORDIAL E DENSIDADE DE MATÉRIA BARIÔNICA
}

\author{
Brenda Pinheiro Carneiro ${ }^{1}$; Rainer Karl Madejsky² . \\ 1. Bolsista PIBIC/CNPq, Graduando em Bacharelado em Física, Universidade Estadual de Feira de Santana, e-mail: \\ brendapinheiroc@gmail.com \\ 2. Orientador, Departamento de Física, Universidade Estadual de Feira de Santana, e-mail: madejsky@uefs.br
}

\section{INTRODUÇÃO}

O estudo detalhado da nucleossíntese primordial- da síntese do hélio e do deutérioé um dos pilares do Modelo Cosmológico Padrão - FLRW (MCP). O Universo evolui de um estado inicial super denso e quente onde as reações nucleares acontecem, mas não se mantém por conta da instabilidade das partículas. Durante esse período primordial, o Universo foi dominado por radiação e sua densidade era inversamente proporcional ao fator de escala do universo (determinado pelas equações de Friedmann-Lemaître) elevado à quarta potência $\left(\rho \sim S^{-4}\right)$. Quando o Universo tem uma idade de um segundo a temperatura, diminuindo atinge um valor adequado. As primeiras reações entre prótons e nêutrons começam a acontecer para poder formar o deutério (d), um isótopo do hidrogênio $(\mathrm{H})$, que além de um próton tem também um nêutron. Essas produções são ótimos indicativos, e o MCP consegue explica-las.

Como não se é conhecido outros processos de produção de deutério, todo o deutério detectado nas galáxias foi produzido durante a nucleossíntese primordial, e esse deutério contém informações de como era o universo nesse período. O estudo desse isótopo é de extrema importância para podermos conhecer melhor as condições iniciais em que o universo se encontrava. A detecção de qualquer abundância de deutério é indicação que a nucleossíntese primordial o produziu, já que praticamente todo deutério produzido na nucleossíntese acaba se transformando em ${ }^{4} \mathrm{He}$ [2], ou então é destruído em colisões com outros prótons e fótons. Os dois processos mais comuns para se destruir deutério são: 1) fótons incidindo sobre os núcleos de deutério (fotodesintegração), e 2) prótons colidindo com núcleos de deutério. A taxa tanto da produção, quanto da destruição do deutério determinam o quão abundante esse núcleo é.

Após a síntese do deutério, quando este já foi formado em quantidades significativas, ainda existiam muitos fótons com energia suficiente para destruir núcleos de deutério. A radiação cósmica de fundo $(\mathrm{RCF})$, resultante de uma época em que o Universo era quente e denso, sendo uma das mais fortes evidências observacionais do modelo do Big Bang, que descreve a evolução do universo. As medidas da radiação cósmica de fundo (WMAP - 2002) nos dizem diretamente qual é o número de fótons por unidade de volume hoje, e com esses valores sabemos quantos fótons havia no momento da nucleossíntese, utilizando as equações de Friedmann. O tempo de vida do deutério é curto, e tem o valor mais baixo possível, já que os prótons são os constituintes mais abundantes. Em qualquer ambiente em que o deutério pode ser produzido, ele também pode ser destruído. A densidade do Universo é dada pelo inverso do tempo de vida do deutério, $\rho_{b}=\frac{1}{t_{D}}$. 


\section{MATERIAL E MÉTODOS}

Consulta da literatura original e de livros-texto. Serão analisados os métodos e conceitos físicos relevantes na discussão da nucleossíntese dos processos nucleares e da dinâmica do universo de acordo com o modelo cosmológico padrão. A abordagem aos cálculos foi com métodos matemáticos analíticos e quando necessário complementado com métodos gráficos e numéricos.

Os métodos analíticos compreendem cálculo diferencial e integral, solução de equações diferenciais, análise das densidades de prótons e nêutrons e da densidade de matéria e da temperatura do universo.

\section{RESULTADOS E DISCUSSÃO}

Para conhecer quantos núcleos de deutério são destruídos através da fotodissociação é necessário conhecer o valor de $\eta$, e conhecer este valor implica em conhecer o números de núcleons no universo. Para estimarmos o valor de $N_{\gamma}$, é necessário conhecer o valor de $\varepsilon$, que é a energia média dos fótons, e $\beta(\lambda)$ que é a equação de Planck [3] para radiação de corpo negro.

$$
\beta(\lambda)=\frac{8 \pi \hbar c}{\lambda^{5}} \frac{1}{e^{\frac{\hbar c}{\lambda k T}}-1}
$$

Sendo conhecidos então os valores de $\lambda$ e $\mathrm{T}$, que são obtidos pela RCF, podemos então estimar o valor de $\eta$ que nos dá a razão entre o número de bárions $\left(N_{b}\right)$ e o número de fótons $\left(N_{Y}\right)$, existentes no Universo no período da nucleossíntese primordial, e conservado até hoje, já que, como foi dito anteriormente, não houve criação ou destruição de bárions e fótons. O valor de $N_{b}$ é obtido através da densidade de matéria barionica.

$$
\eta=\frac{N_{b}}{N_{\gamma}} \sim 10^{-9}
$$

Partindo de estudos da nucleossíntese primordial, analisando a radiação cósmica de fundo (RCF), conclui-se que para cada núcleo de deutério, existiam $10^{9}$ fótons, sendo uma quantidade suficiente para destruir núcleos de deutério, mesmo quando a temperatura do Universo diminuiu. Observando o valor de $\eta$, percebemos que, somente uma pequena fração dos fótons precisa ter energia suficiente para foto dissociar os dêuterons.

Para estimar quantos deutérios são destruídos em colisões com prótons, dependemos basicamente da velocidade que tem esse próton. Essa velocidade pode ser estudada e interpretada pela distribuição Maxwelliana [1], que é também uma distribuição gaussiana. Essa velocidade depende apenas da massa do próton, e sua temperatura. $\mathrm{O}$ número de colisões que ocorrem por tempo, consequentemente, o inverso do tempo de vida do deutério $\left(t_{D}\right)[4]$, pode ser estimado por:

$$
\frac{1}{t_{D}}=n_{p}\langle\sigma v\rangle_{D}
$$

Sendo $\sigma$, a seção transversal do próton, igual a $\pi \mathrm{r}^{2}, \mathrm{n}$ o número de prótons por volume, e v a velocidade do próton. Como todos os valores são conhecidos, então é possível estimar aproximadamente, o tempo de vida do deutério, e quanto deutério é 
destruído em colisões com prótons. Feito então as estimativas, chegamos ao resultado que:

$$
\frac{1}{t_{D}} \sim \frac{10^{6}}{s}
$$

A quantidade de deutério destruído pelas colisões num modelo aberto é reduzida portanto, a quantidade de deutério resultante num modelo aberto aumenta. Uma vez que muito pouco deutério sobrevive no modelo fechado, em relação ao aberto, concluímos que ou o universo é aberto ou ele não segue o modelo cosmológico padrão. Já que a densidade do Universo é dada pelo inverso do tempo de vida do deutério, então quanto maior for a densidade bariônica $\left(\rho_{b}\right)$, menor é o valor de $t_{D}$, e consequentemente, quanto menor for $\rho_{b}$, maior é o valor de $t_{D}$.

\section{CONSIDERAÇÕES FINAIS}

O deutério é o indicador mais sensível de matéria bariônica. Uma densidade bariônica maior implica mais altas taxas de reações nucleares, uma vez que há mais tempo para síntese de hélio-4, em um Universo de alta densidade em comparação a um Universo de baixa densidade que expande mais rapidamente. Essa densidade bariônica maior também implica mais colisões entre os bárions, destruindo assim mais deutério, por causa da sua baixa energia de ligação. Logo, sendo a abundância do deutério é muito sensível a essa densidade, como já foi dito anteriormente, um modelo aberto de universo (com a densidade baixa) produz uma grande quantidade de deutério, já em um modelo

fechado de universo (com a densidade hoje maior que $10^{-30} \mathrm{~g} / \mathrm{cm}^{3}$ ) produz muito pouco deutério.

Uma vez que muito pouco deutério sobrevive no modelo fechado, em relação ao aberto, concluímos que a matéria bariônica detectada não é suficiente para obedecer o modelo fechado de Universo, já que a análise detalhada, de acordo com o modelo cosmológico padrão, mostra que apenas $4 \%$ da densidade crítica do universo pode ser matéria bariônica. Devido à rápida expansão e devido ao esfriamento do Universo, a nucleossíntese termina com a produção de $25 \%$ de hélio (em massa), começando depois de 200 milhões de anos, com a formação das primeiras estrelas, a outra fase da nucleossíntese conhecida como nucleossíntese estrelar.

\section{REFERÊNCIAS}

[1] MADEJSKY, K. Rainer. Curso básico de astrofísica e cosmologia: 1- O sistema solar, as estrelas e a Via Láctea. Feira de Santana: UEFS Editora, 2014. 360 p.

[2] JONES, M.H., LAMBOURNE, R.J.A. Galaxies and Cosmology. Cambridge University Press, 2004.

[3] CARUSO, F. e OGURI V., Física Moderna - Origens Clássicas e Fundamentos Quânticos, Ed. Campus, Rio de Janeiro, 2006.

[4] DURIC, N., Advanced Astrophysic. Cambridge University Press, 2004. 